\title{
Image-derived input functions for PET brain studies
}

\author{
Jurgen E. M. Mourik • Mark Lubberink • \\ Alie Schuitemaker • Nelleke Tolboom • \\ Bart N. M. van Berckel • Adriaan A. Lammertsma • \\ Ronald Boellaard
}

Received: 1 August 2008 /Accepted: 9 October 2008 / Published online: 22 November 2008

(C) Springer-Verlag 2008

\begin{abstract}
Purpose To assess the robustness of a previously introduced method to obtain accurate image-derived input functions (IDIF) for three other tracers.

Methods Dynamic PET and online blood data of five repeat $\left[{ }^{11} \mathrm{C}\right] \mathrm{PIB}$ (Pittsburgh Compound-B) $\left(\left[{ }^{11} \mathrm{C}\right] \mathrm{PIB}\right)$, six repeat $(R)-\left[{ }^{11} \mathrm{C}\right]$ verapamil, and ten single $(R)-\left[{ }^{11} \mathrm{C}\right] \mathrm{PK} 11195$ studies were used. IDIFs were extracted from partial volume corrected scans using the four hottest pixels per plane method. Results obtained with IDIFs were compared with those using standard online measured arterial input functions (BSIF). IDIFs were used both with and without calibration based on manual blood samples.

Results For $(R)-\left[{ }^{11} \mathrm{C}\right]$ verapamil, accurate IDIFs were obtained using noncalibrated IDIFs (slope $0.96 \pm 0.17 ; R^{2}$ $0.92 \pm 0.07$ ). However, calibration was necessary to obtain IDIFs comparable to the BSIF for both $\left[{ }^{11} \mathrm{C}\right] \mathrm{PIB}$ (slope $1.04 \pm 0.05 ; R^{2} 1.00 \pm 0.01$ ) and $(R)-\left[{ }^{11} \mathrm{C}\right] \mathrm{PK} 11195$ (slope $0.96 \pm 0.05 ; R^{2} 0.99 \pm 0.01$ ). The need for calibration may be explained by the sticking property of both tracers, indicating that BSIF may be affected by sticking and therefore may be unreliable.

Conclusion The present study shows that a previously proposed method to extract IDIFs is suitable for analysing
\end{abstract}

J. E. M. Mourik $(\bowtie) \cdot$ M. Lubberink · A. Schuitemaker

N. Tolboom - B. N. M. van Berckel - A. A. Lammertsma •

R. Boellaard

Department of Nuclear Medicine and PET Research,

VU University Medical Center,

P.O. Box 7057, 1007 MB Amsterdam, The Netherlands

e-mail: j.mourik@vumc.nl

A. Schuitemaker $\cdot$ N. Tolboom

Department of Neurology, VU University Medical Center,

Amsterdam, The Netherlands $\left[{ }^{11} \mathrm{C}\right] \mathrm{PIB},(R)-\left[{ }^{11} \mathrm{C}\right]$ verapamil and $(R)-\left[{ }^{11} \mathrm{C}\right] \mathrm{PK} 11195$ studies, thereby obviating the need for online arterial sampling.

Keywords PET - Image-derived input function .

Partial volume correction · Sticking of $\left[{ }^{11} \mathrm{C}\right] \mathrm{PIB}$

\section{Introduction}

Positron emission tomography (PET) is a medical imaging technique that is used to study tissue function in vivo by imaging and measuring regional tracer concentrations of tracer labelled with positron-emitting radionuclides. A tracer kinetic model is needed to derive the tissue response function from these measurements. Tracer kinetic modelling also requires measurement of the tracer time-course in plasma, unless a reference tissue $[1,2]$ can be found in which specific tracer uptake is absent. In general, arterial sampling is considered to be the gold standard for obtaining the arterial input function. However, arterial sampling is invasive, laborious and sensitive to errors, and has a minor risk of adverse effects [3, 4]. A number of alternative methods have been suggested, including those extracting the input function from the dynamic PET images themselves, a so-called image-derived input function (IDIF) [5]. In a previous study [6], a new method was developed that combines partial volume correction (PVC) during reconstruction with a simple automatic procedure for extracting the IDIF from the internal carotid arteries. PVC is necessary to recover the true radioactivity due to the limited spatial resolution of most PET scanners. Although the new method is not truly noninvasive, with manual blood samples still being necessary for calibration and metabolite analysis, it is an important step towards a fully noninvasive alternative to online arterial sampling. 
The previously developed method was, however, only validated on a dataset of ten $\left[{ }^{11} \mathrm{C}\right]$ flumazenil scans [6] for the ECAT EXACT HR+ scanner (CTI/Siemens, Knoxville, $\mathrm{TN})$ and six $\left[{ }^{11} \mathrm{C}\right]$ flumazenil scans [7] for the highresolution research tomograph (CTI/Siemens). Other tracers show different activity uptake, distribution and contrast, resulting in a different partial volume effect and scatter distribution. Consequently, the previously proposed method may not necessarily provide similar accuracy for difference tracers. The aim of the present study was to further evaluate the accuracy of the proposed method for three other tracers, $\left[{ }^{11} \mathrm{C}\right] \mathrm{PIB}$ (Pittsburgh Compound-B) $\left(\left[{ }^{11} \mathrm{C}\right] \mathrm{PIB}\right),(R)-\left[{ }^{11} \mathrm{C}\right]$ verapamil and $(R)-\left[{ }^{11} \mathrm{C}\right] \mathrm{PK} 11195$. A second aim was to assess whether test-retest variability was affected by using IDIFs.

\section{Materials and methods}

\section{Subjects}

Data from five test-retest $\left[{ }^{11} \mathrm{C}\right] \mathrm{PIB}$, six test-retest $(R)-\left[{ }^{11} \mathrm{C}\right]$ verapamil, and ten single $(R)-\left[{ }^{11} \mathrm{C}\right] \mathrm{PK} 11195$ studies were used. Both $\left[{ }^{11} \mathrm{C}\right] \mathrm{PIB}$ and $(R)-\left[{ }^{11} \mathrm{C}\right]$ verapamil test and retest scans were performed on the same day. $\left[{ }^{11} \mathrm{C}\right] \mathrm{PIB}$ is a PET tracer that enables visualization of accumulation of amyloid$\beta$ in patients with Alzheimer's disease [8]. $(R)-\left[{ }^{11} \mathrm{C}\right]$ verapamil is a tracer for measuring $\mathrm{P}$-glycoprotein function in vivo, which may play an important role in several neurological disorders such as Alzheimer's disease [9] and normal ageing [10]. Finally, $(R)-\left[{ }^{11} \mathrm{C}\right] \mathrm{PK} 11195$ is a marker of activated microglia, which is used to measure inflammation in neurological disorders [11].

All data for the three different tracers were acquired in ongoing clinical research studies which had been approved by the Medical Ethics Committee of the VU University Medical Center, and all subjects had given written informed consent prior to scanning.

Scan procedures

Scans were acquired using a HR+ whole-body PET scanner. Before tracer administration, a 10-min transmission scan was acquired in 2-D mode using three rotating ${ }^{68} \mathrm{Ge} /{ }^{68} \mathrm{Ga}$ sources, which was used to correct the subsequent emission scans for attenuation. Subsequently, a dynamic emission scan was acquired in 3-D acquisition mode, following bolus injection of the tracer. The number of included scans, injected doses (Table 1), scan duration and frame definition (Table 2) differed for each tracer. Note that the first frame $(30 \mathrm{~s})$ of the $\left[{ }^{11} \mathrm{C}\right] \mathrm{PK} 11195$ scan was a background frame. During the emission scan the arterial input function was measured using a continuous flowthrough automatic blood sampling device [12]. At set times (Table 1), continuous withdrawal was interrupted briefly for the collection of manual samples and after each sample (except the first) the arterial line was flushed with heparinized saline. These manual samples were used for recalibrating the (online) blood sampler, for measuring plasma to whole-blood ratios, and for determining plasma metabolite fractions. $\left[{ }^{11} \mathrm{C}\right] \mathrm{PIB}$ and $(R)-\left[{ }^{11} \mathrm{C}\right]$ verapamil scans were part of test-retest protocols where the whole scan procedure was repeated approximately $4 \mathrm{~h}$ after the start of the first scan.

\section{Reconstruction-based partial volume correction}

A previously described [6] reconstruction-based PVC method was used to recover the true radioactivity concentration of the internal carotid arteries. Optimal settings (four iterations, 16 subsets and $4.5-\mathrm{mm}$ Gaussian resolution kernel) for the PVC reconstruction, as determined previously [6], were used.

\section{Reconstruction}

All data were normalized and corrected for random coincidences, scattered radiation, dead time and decay, and were reconstructed with an in-house developed PVC ordered subset expectation maximization (PVC-OSEM, four iterations, 16 subsets) algorithm. Additionally, all data were reconstructed using the standard (no PVC) normalization and attenuation-weighted OSEM (NAW-OSEM, two iterations, 16 subsets) algorithm (ECAT 7.2 software; CTI/ Siemens) and smoothed afterwards with a Gaussian kernel of $5 \mathrm{~mm}$, resulting in an image resolution of $7 \mathrm{~mm}$ FWHM. These NAW-OSEM scans were only used for region of interest (ROI) definition. All reconstructed images consisted of 63 planes of $256 \times 256$ voxels with a voxel size of $1.29 \times 1.29 \times 2.43 \mathrm{~mm}^{3}$.

Table 1 Number of scans, injected dose (means \pm standard deviation) and manual sampling times

\begin{tabular}{llll}
\hline Tracer & No. of scans & Injected dose $(\mathrm{MBq})$ & Manual sampling times (min) \\
\hline$\left[{ }^{11} \mathrm{C}\right] \mathrm{PIB}$ & $5+5$ & $348 \pm 66$ & $5,10,20,40,60,75,90$ \\
$(R)-\left[{ }^{11} \mathrm{C}\right]$ Verapamil & $6+6$ & $366 \pm 32$ & $2.5,5,10,20,30,40,60$ \\
$(R)-\left[{ }^{11} \mathrm{C}\right]$ PK11195 & 10 & $411 \pm 42$ & $3,6,10,20,30,40,60$ \\
\hline
\end{tabular}


Table 2 Number of frames, scan duration and frame length definition

\begin{tabular}{llll}
\hline Tracer & No. of frames & Scan time (min) & Frame lengths $(\mathrm{s})$ \\
\hline$\left[{ }^{11} \mathrm{C}\right] \mathrm{PIB}$ & 23 & 90.0 & $1 \times 15,3 \times 5,3 \times 10,2 \times 30,3 \times 60,2 \times 150,2 \times 300,7 \times 600$ \\
$(R)-\left[{ }^{11} \mathrm{C}\right]$ Verapamil & 20 & 60.0 & $1 \times 15,3 \times 5,3 \times 10,2 \times 30,3 \times 60,2 \times 150,2 \times 300,4 \times 600$ \\
$(R)-\left[{ }^{11} \mathrm{C}\right]$ PK11195 & 22 & 60.5 & $1 \times 30,1 \times 15,1 \times 5,1 \times 10,2 \times 15,2 \times 30,3 \times 60,4 \times 150,5 \times 300,2 \times 600$ \\
\hline
\end{tabular}

Extraction of image-derived whole-blood time-activity curve

ROIs for extracting the image-derived whole-blood timeactivity curve (TAC) were defined on a volume of 11 planes, starting at three planes below the circle of Willis. This volume $\left(177.7 \mathrm{~mm}^{3}\right)$ corresponds to the position of the carotid arteries and is located outside the skull to avoid contamination (spill-in) of activity from the brain. ROIs were (semi)automatically defined on pseudo blood volume images derived from the summation of very early time frames of the NAW-OSEM images (15 to $60 \mathrm{~s}$ after injection) using the 'four hottest pixels per plane' $\left(6.7 \mathrm{~mm}^{2}\right.$ per plane) method. These ROIs were projected onto each frame of the PVC-OSEM images. The imagederived whole-blood TAC was generated as the time sequence of the averaged ROI values.

\section{Corrections and calibration}

Blood sampler whole-blood curves were corrected for delay and calibrated using the manual samples. Delay of the online measured input function was obtained by fitting a plasma input single tissue compartment model including a blood volume fraction to the total cerebral grey matter TAC [13]. The first 300 to $600 \mathrm{~s}$ of this TAC were used such that it could be well described by a single-tissue compartment model. In this step, the following fit parameters were used: $\mathrm{K}_{1}, \mathrm{~V}_{\mathrm{T}}, \mathrm{V}_{\mathrm{b}}$ (blood volume fraction) and delay [13]. In this way, delay values were not affected by dispersion of the input function because the blood volume fraction parameter accounted for dispersion as well. Image-derived wholeblood TACs were used both without and with calibration to the manual samples. Calibration was performed using a multiexponential function that was first fitted through the image-derived whole-blood TAC from 1,000 to $3,600 \mathrm{~s}$. Next this function was multiplied by a 'calibration factor' such that it fitted through the manual sample data using residual squared error as optimization parameters. The 'calibration factor' was then applied to the image-derived whole-blood TAC. In this way statistical errors in the image-derived whole-blood TAC at corresponding manual blood sample withdrawal times were avoided.

In addition, both blood sampler whole-blood curves and image-derived whole-blood TACs were corrected for plasma to whole-blood ratios and metabolites. The plasma to whole-blood ratio was calculated for each manual blood sample and next a one- or two-exponential function was fitted through these points. Metabolite correction was performed by multiplication of the plasma curve with a Hill-type function, obtained from a fit to the measured parent fraction, resulting in blood sampler input functions (BSIFs) and IDIFs (with and without calibration). This Hilltype function is given by $P(t)=\frac{\alpha t^{\beta}}{t^{\beta}+\gamma}$, where $\mathrm{P}(\mathrm{t})$ is the parent fraction in plasma as function of time $t$, and $\alpha, \beta$ and $\gamma$ are fit parameters $[14,15]$.

Data analysis

For all tracers, areas under the curve (AUC) for both peak (0-6 $\mathrm{min})$ and tail $(6-60 \mathrm{~min})$ were calculated for both BSIF and IDIF. In addition, AUC ratios between IDIF and BSIF were calculated. Parametric Logan [16] volume of distribution $\left(\mathrm{V}_{\mathrm{T}}\right)$ analysis was performed for both $\left[{ }^{11} \mathrm{C}\right] \mathrm{PIB}$ [8] and $(R)-\left[{ }^{11} \mathrm{C}\right] \mathrm{PK} 11195$ [17] data. Previously, it has been shown that Logan analysis is not optimal for analysing $(R)$ $\left[{ }^{11} \mathrm{C}\right]$ verapamil because of the significant contribution of intravascular activity. Therefore, for $(R)-\left[{ }^{11} \mathrm{C}\right]$ verapamil, $\mathrm{V}_{\mathrm{T}}$ was determined using a basis function method implementation $[19,20]$ of the single-tissue compartment model.

For all tracers, a total of 15 ROIs were drawn manually on $\mathrm{V}_{\mathrm{T}}$ images, using the software package Display (http:// www.bic.mni.mcgill.ca/software/Display/Display.html, Montreal Neurological Institute). ROIs were drawn in anatomical areas with varying levels of uptake (frontal, temporal and occipital cortex, white matter, thalamus, putamen, cerebellum and pons). Mean $\mathrm{V}_{\mathrm{T}}$ values for all anatomical regions were calculated for both BSIF and IDIF. Mean parametric values of BSIF were plotted against corresponding IDIF values. Slope, intercept and squared Pearson's correlation coefficient $\left(R^{2}\right)$ were calculated for each subject.

\section{Test-retest variability}

Retest scans were automatically coregistered on test scans using the Vinci software package, which was kindly provided by the Max Planck Institute for Neurological Research (Cologne, Germany; http://www.mpifnf.de/vinci/). The intrasubject test-retest variability for 15 ROIs per 

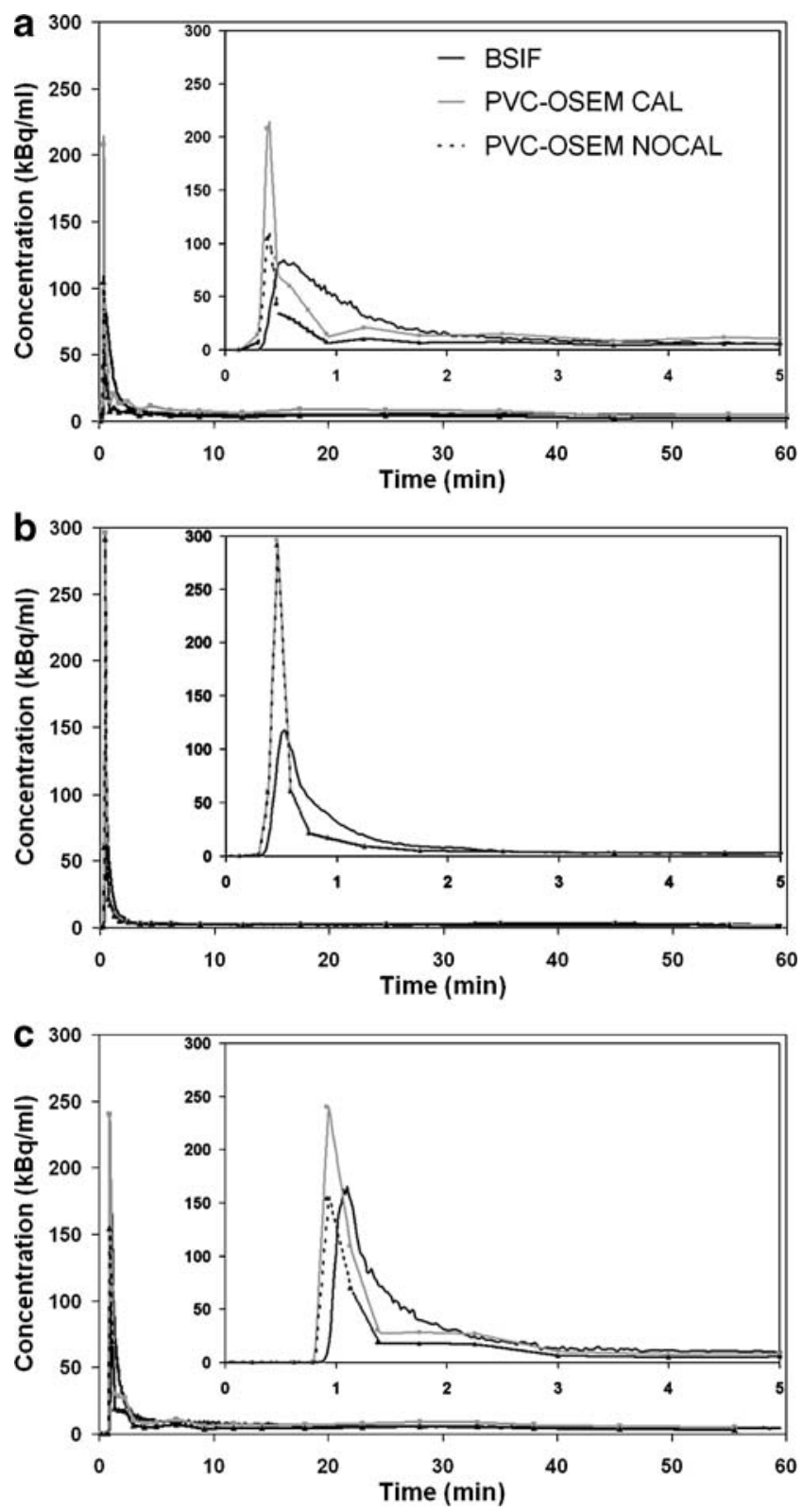

Fig. 1 Typical BSIF and (non)calibrated IDIF extracted from PVCOSEM images for (a) $\left[{ }^{11} \mathrm{C}\right] \mathrm{PIB}$, (b) $(R)-\left[{ }^{11} \mathrm{C}\right]$ verapamil, and (c) $(R)$ $\left[{ }^{11} \mathrm{C}\right] \mathrm{PK} 11195$. BSIF and IDIF for the first $5 \mathrm{~min}$ are shown as inserts subject was calculated as the difference between test and retest mean ROI values divided by the mean of those test and retest values. Test-retest variability was calculated for both BSIF and IDIF.

Sticking experiment

As discussed below, due to the lipophilicity of $\left[{ }^{11} \mathrm{C}\right] \mathrm{PIB}$, a sticking experiment was necessary. This experiment is of importance as sticking of a tracer to the tubing could affect the quality of the BSIF and thereby affect the validation of the IDIF for this tracer. The potential sticking of $\left[{ }^{11} \mathrm{C}\right] \mathrm{PIB}$ was investigated using an experiment that simulated the clinical situation of automatic arterial sampling. Three infusion bags were connected, one at a time, to the automated sampling device by a PTFE tube, which is also used in patient studies. The infusion bags were filled with a $\mathrm{NaCl}$ solution. A high concentration (about $250 \mathrm{kBq} / \mathrm{ml}$ ) of $\left[{ }^{11} \mathrm{C}\right] \mathrm{PIB}$ was added to the first infusion bag, "simulating" a bolus injection (peak of input function). The concentration of $\left[{ }^{11} \mathrm{C}\right] \mathrm{PIB}$ added to the second infusion bag was at least ten times lower (about $20 \mathrm{kBq} / \mathrm{ml}$ ) than that of the first infusion bag, thus "simulating" the tail of the input function. Finally, the third infusion bag contained no $\left[{ }^{11} \mathrm{C}\right]$ $\mathrm{PIB}$ and therefore only contained $\mathrm{NaCl}$. As a reference, the experiment was repeated for the nonsticking tracer $\left[{ }^{18} \mathrm{~F}\right]$ FDG.

\section{Results}

Typical BSIF and IDIF for $\left[{ }^{11} \mathrm{C}\right] \mathrm{PIB},(R)-\left[{ }^{11} \mathrm{C}\right]$ verapamil and $(R)-\left[{ }^{11} \mathrm{C}\right] \mathrm{PK} 11195$ are shown in Fig. 1 . For all tracers, the peak of the IDIF was reached slightly earlier and was much sharper than that of the BSIF (see inserts in Fig. 1). Note that the differences in the shape of the peak between BSIF and IDIF is caused by dispersion of the BSIF resulting in a wider and lower peak of BSIF. BSIF and IDIF were very similar at later times.
Fig. 2 Mean (a) peak and (b) tail AUC ratios between IDIF and BSIF for $\left[{ }^{11} \mathrm{C}\right] \mathrm{PIB},(R)$ $\left[{ }^{11} \mathrm{C}\right]$ verapamil and $(R)-\left[{ }^{11} \mathrm{C}\right]$ PK11195. Error bars represents the SD between subjects a

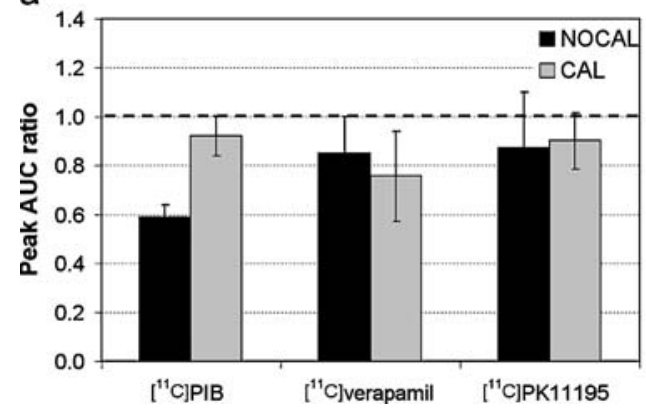

b

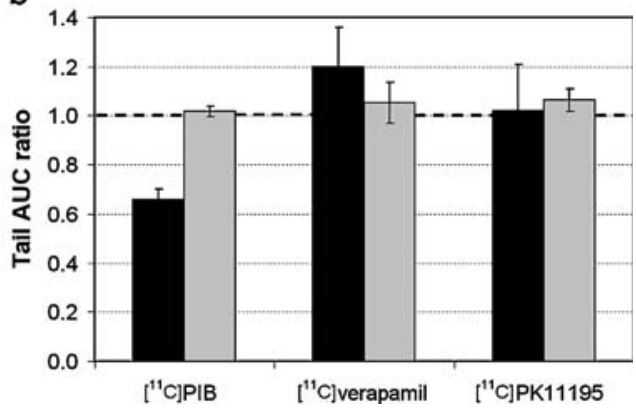



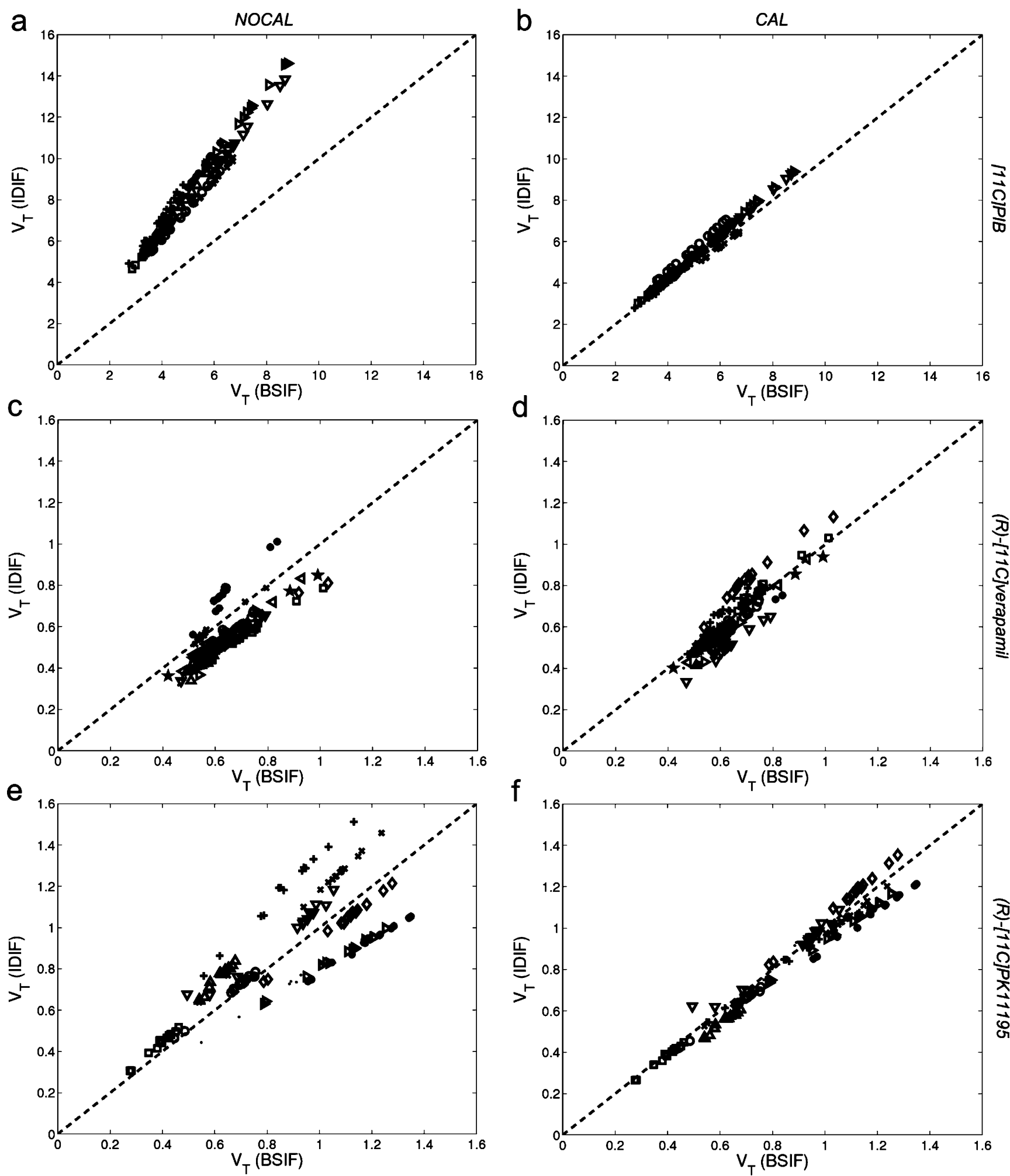

Fig. 3 Correlation between $V_{T}$ values using BSIF and noncalibrated $(\mathbf{a}, \mathbf{c}, \mathbf{e})$ and calibrated $(\mathbf{b}, \mathbf{d}, \mathbf{f}) \operatorname{IDIFs}$ for $\left[{ }^{11} \mathrm{C}\right] \mathrm{PIB}(\mathbf{a}, \mathbf{b}),(R)-\left[{ }^{11} \mathrm{C}\right]$ a single subject; the same symbol per subject represents different anatomical regions (dashed line line of identity) 


\section{AUC ratios}

Mean peak and tail AUC ratios for all tracers are shown in Fig. 2. When using IDIFs without calibration, the AUCs of the peak were underestimated for all tracers (Fig. 2a), ranging from $12 \%$ for $(R)-\left[{ }^{11} \mathrm{C}\right] \mathrm{PK} 11195$ to $40 \%$ for $\left[{ }^{11} \mathrm{C}\right]$ PIB. Good peak AUC ratios were found using calibrated IDIFs for $\left[{ }^{11} \mathrm{C}\right] \mathrm{PIB}(0.92 \pm 0.08)$ and $(R)-\left[{ }^{11} \mathrm{C}\right] \mathrm{PK} 11195$ $(0.90 \pm 0.12)$. For $(R)-\left[{ }^{11} \mathrm{C}\right]$ verapamil, better peak AUC ratios $(0.85 \pm 0.15)$ were found when noncalibrated IDIFs were used compared with calibrated IDIFs $(0.75 \pm 0.18)$. Differences in tail AUC ratios (Fig. 2b) between noncalibrated and calibrated IDIFs were large for $\left[{ }^{11} \mathrm{C}\right] \mathrm{PIB}$ (not calibrated $0.59 \pm 0.04$; calibrated $1.02 \pm 0.02)$ and $(R)-\left[{ }^{11} \mathrm{C}\right]$ verapamil (not calibrated 1.20 \pm 0.16 ; calibrated $1.05 \pm 0.08$ ). By definition, the tail AUC ratio of calibrated IDIFs was close to 1.0 for all tracers.

Tracer kinetic analysis

Figure 3 shows a comparison of regional $\mathrm{V}_{\mathrm{T}}$ obtained using BSIF and non-calibrated (a, c, e) and calibrated (b, d, f) IDIFs for $\left[{ }^{11} \mathrm{C}\right] \mathrm{PIB}(\mathrm{a}, \mathrm{b}),(R)-\left[{ }^{11} \mathrm{C}\right]$ verapamil $(\mathrm{c}, \mathrm{d})$ and $(R)-\left[{ }^{11} \mathrm{C}\right] \mathrm{PK} 11195(\mathrm{e}, \mathrm{f})$. Large differences in $\mathrm{V}_{\mathrm{T}}$ values between non-calibrated and calibrated IDIFs were found for $\left[{ }^{11} \mathrm{C}\right]$ PIB (Fig. 3a,b).

Mean slope, intercept and $R^{2}$ values over all subjects for $\left[{ }^{11} \mathrm{C}\right] \mathrm{PIB},(R)-\left[{ }^{11} \mathrm{C}\right]$ verapamil and $(R)-\left[{ }^{11} \mathrm{C}\right] \mathrm{PK} 11195$ can be found in Table 3 . For $\left[{ }^{11} \mathrm{C}\right] \mathrm{PIB}$, very large slope values $(1.61 \pm 0.13)$ were found for noncalibrated IDIFs, but excellent results for calibrated IDIFs (slope 1.04 \pm 0.05 ; intercept $\left.0.00 \pm 0.17 ; R^{2} 1.00 \pm 0.01\right)$. For $(R)-\left[{ }^{11} \mathrm{C}\right]$ verapamil, slope, intercept and $R^{2}$ values were comparable for noncalibrated $(0.96 \pm 0.17)$ and calibrated IDIFs $(1.08 \pm 0.15)$. For $(R)-\left[{ }^{11} \mathrm{C}\right] \mathrm{PK} 11195$, excellent intercept, $R^{2}$ and slope values were found for both calibrated (slope $0.96 \pm 0.05$ ) and noncalibrated IDIFs (slope $1.03 \pm 0.21$ ), but the latter had a much higher intersubject variability (compare Fig. 3e and f).

Figure 4 shows the $\left[{ }^{11} \mathrm{C}\right] \mathrm{PIB}$ prefrontal Logan $\mathrm{V}_{\mathrm{T}}$ values for BSIF and (non)calibrated IDIFs and the differences in $\left[{ }^{11} \mathrm{C}\right] \mathrm{PIB}$ binding amongst patients and healthy controls (indicated with different symbols). This figure illustrates

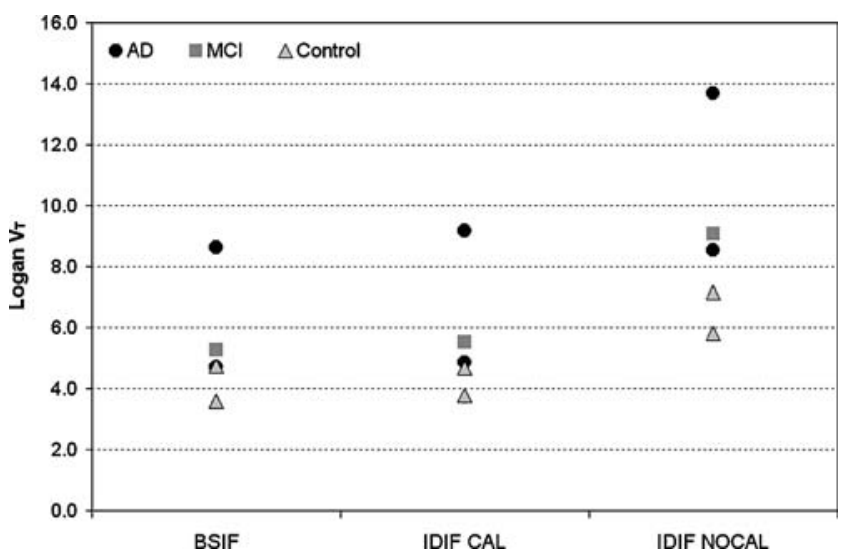

Fig. $4\left[{ }^{11} \mathrm{C}\right] \mathrm{PIB}$ prefrontal Logan $\mathrm{V}_{\mathrm{T}}$ values for patients with Alzheimer's disease $(A D)$ and mild cognitive impairment $(M C I)$ and healthy controls based on BSIF and calibrated and noncalibrated IDIFs

that the discrimination between patients and healthy controls was similar (IDIF CAL) or even better (IDIF NOCAL) compared with BSIF.

\section{Test-retest variability}

Mean test-retest variabilities for both $\left[{ }^{11} \mathrm{C}\right] \mathrm{PIB}$ and $(R)$ $\left[{ }^{11} \mathrm{C}\right]$ verapamil using BSIF, noncalibrated and calibrated IDIFs are shown in Table 4. For $\left[{ }^{11} \mathrm{C}\right] \mathrm{PIB}$, the highest testretest variability $(0.13 \pm 0.11)$ was found for calibrated IDIFs. The best test-retest variability was found for noncalibrated IDIFs $(0.08 \pm 0.07)$. Significantly higher testretest variabilities were found for BSIF $(p<0.05)$ and calibrated IDIFs $(p<0.001)$. For $(R)-\left[{ }^{11} \mathrm{C}\right]$ verapamil, the test-retest variabilities of BSIF and calibrated IDIF were comparable. Although a slightly higher test-retest variability was found for noncalibrated IDIFs (Table 4), this was not significantly different from that for calibrated IDIFs $(p>0.07)$.

\section{Sticking experiment}

Due to the lipophilicity of $\left[{ }^{11} \mathrm{C}\right] \mathrm{PIB}$ some sticking may be present, which may explain the large difference in AUC and $\mathrm{V}_{\mathrm{T}}$ results between noncalibrated and calibrated IDIFs.

Table 3 Overview of mean slope, intercept and $R^{2}$ between BSIF and (non)calibrated IDIF based $\mathrm{V}_{\mathrm{T}}$ for $\left[{ }^{11} \mathrm{C}\right] \mathrm{PIB},(R)-\left[{ }^{11} \mathrm{C}\right]$ verapamil and $(R)-\left[{ }^{11} \mathrm{C}\right] \mathrm{PK} 11195$

\begin{tabular}{lllll}
\hline Tracer & IDIF & Slope & Intercept & $R^{2}$ \\
\hline$\left[{ }^{11} \mathrm{C}\right] \mathrm{PIB}$ & Noncalibrated & $1.61 \pm 0.13$ & $0.01 \pm 0.27$ & $1.00 \pm 0.01$ \\
& Calibrated & $1.04 \pm 0.05$ & $0.00 \pm 0.17$ & $1.00 \pm 0.01$ \\
$(R)-\left[{ }^{11} \mathrm{C}\right]$ verapamil & Noncalibrated & $0.96 \pm 0.17$ & $-0.05 \pm 0.07$ & $0.92 \pm 0.07$ \\
$(R)-\left[{ }^{11} \mathrm{C}\right] \mathrm{PK} 11195$ & Calibrated & $1.08 \pm 0.15$ & $-0.06 \pm 0.09$ & $0.92 \pm 0.07$ \\
& Noncalibrated & $1.03 \pm 0.21$ & $0.01 \pm 0.05$ & $0.99 \pm 0.01$ \\
& Calibrated & $0.96 \pm 0.05$ & $0.01 \pm 0.05$ & $0.99 \pm 0.01$ \\
\hline
\end{tabular}


Table 4 Mean test-retest variability of $\mathrm{V}_{\mathrm{T}}$ over all subjects for $\left[{ }^{11} \mathrm{C}\right]$ PIB and $(R)-\left[{ }^{11} \mathrm{C}\right]$ verapamil

\begin{tabular}{lll}
\hline & {$\left[{ }^{11} \mathrm{C}\right] \mathrm{PIB}$} & $(R)-\left[{ }^{11} \mathrm{C}\right]$ verapamil \\
\hline BSIF & $0.10 \pm 0.08$ & $0.07 \pm 0.05$ \\
Non-calibrated IDIF & $0.08 \pm 0.07$ & $0.10 \pm 0.10$ \\
Calibrated IDIF & $0.13 \pm 0.11$ & $0.07 \pm 0.06$ \\
\hline
\end{tabular}

The sticking property of $\left[{ }^{11} \mathrm{C}\right] \mathrm{PIB}$ was investigated by the sticking experiment described previously.

The decay-corrected measured curves of both $\left[{ }^{11} \mathrm{C}\right] \mathrm{PIB}$ and $\left[{ }^{18} \mathrm{~F}\right]$ FDG are shown in Fig. 5. For $\left[{ }^{11} \mathrm{C}\right] \mathrm{PIB}$ it took at least $2 \mathrm{~min}$ to reach a maximum, while for $\left[{ }^{18} \mathrm{~F}\right] \mathrm{FDG}$ the maximum had already been reached after a few seconds. The same (reversed) pattern was seen when bag 1 (high concentration of $\left.\left[{ }^{11} \mathrm{C}\right] \mathrm{PIB} /\left[{ }^{18} \mathrm{~F}\right] \mathrm{FDG}\right)$ was replaced by bag 2 (lower concentration of $\left[{ }^{11} \mathrm{C}\right] \mathrm{PIB} /\left[{ }^{18} \mathrm{~F}\right] \mathrm{FDG}$ ). The measured $\left[{ }^{18} \mathrm{~F}\right] \mathrm{FDG}$ curve decreased to the lower level within seconds, while for $\left[{ }^{11} \mathrm{C}\right] \mathrm{PIB}$ the decrease took more than $3 \mathrm{~min}$. Furthermore, both the peak and tail of the $\left[{ }^{11} \mathrm{C}\right] \mathrm{PIB}$ curve were much higher than those of $\left[{ }^{18} \mathrm{~F}\right] \mathrm{FDG}$. Finally, when the last infusion bag was connected to the automatic sampling device, the concentration of $\left[{ }^{18} \mathrm{~F}\right] \mathrm{FDG}$ dropped to $0.0 \pm 0.1 \mathrm{kBq}$, while the concentration of $\left[{ }^{11} \mathrm{C}\right] \mathrm{PIB}$ was $3.4 \pm 1.3 \mathrm{kBq} / \mathrm{ml}$. The prolonged up- and down-slopes of the curve confirms sticking of $\left[{ }^{11} \mathrm{C}\right] \mathrm{PIB}$.

\section{Discussion}

\section{Calibration}

Differences in $\mathrm{V}_{\mathrm{T}}$ analysis (Fig. 3) between calibrated and non-calibrated IDIFs for $(R)-\left[{ }^{11} \mathrm{C}\right]$ verapamil were very small, which agrees with the results found for $\left[{ }^{11} \mathrm{C}\right]$

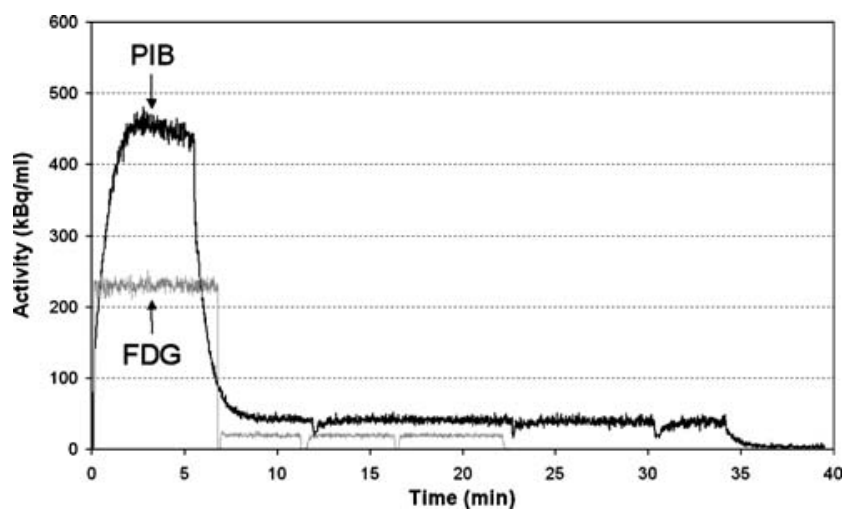

Fig. 5 Experimentally derived input functions of $\left[{ }^{11} \mathrm{C}\right] \mathrm{PIB}$ and $\left[{ }^{18} \mathrm{~F}\right]$ $\mathrm{FDG}$ in $\mathrm{NaCl}$ solution. Both simulated input functions were corrected for decay. The prolonged up- and down-slope of $\left[{ }^{11} \mathrm{C}\right] \mathrm{PIB}$ (dark line) confirm its sticking behaviour flumazenil [6]. However, the best AUC ratios (Fig. 2) were found for calibrated IDIFs. Using calibrated IDIFs, the best peak AUC ratios and $\mathrm{V}_{\mathrm{T}}$ values were found for $\left[{ }^{11} \mathrm{C}\right] \mathrm{PIB}$, while the best $\mathrm{V}_{\mathrm{T}}$ values were only found for $(R)-\left[{ }^{11} \mathrm{C}\right]$ PK11195. The effect of calibrating the IDIF was especially large for $\left[{ }^{11} \mathrm{C}\right] \mathrm{PIB}$ (see Fig. 2 and Table 3).

Of the four tracers investigated to date, calibration is not needed for either $(R)-\left[{ }^{11} \mathrm{C}\right]$ verapamil or $\left[{ }^{11} \mathrm{C}\right]$ flumazenil, but it is essential for $\left[{ }^{11} \mathrm{C}\right] \mathrm{PIB}$ and preferred for $(R)-\left[{ }^{11} \mathrm{C}\right]$ PK11195. The reasons for this difference are not fully understood. One possible explanation is sticking of the tracer to the wall of the arterial tube, which is confirmed by the sticking experiment that was performed (see Fig. 5). Although this experiment was performed with a solution of $\mathrm{NaCl}$, the prolonged down-slope was also visible in the clinical BSIF (Fig. 1a). Based on these experiments and visual examination of the BSIF, it is likely that the shape and amplitude of BSIF was affected by sticking of $\left[{ }^{11} \mathrm{C}\right]$ PIB. Consequently, both BSIF and manual samples may not be reliable. It is clear that noncalibrated IDIFs are not affected by sticking and therefore these IDIFs may be more reliable. This hypothesis is further supported by the fact that for $\left[{ }^{11} \mathrm{C}\right] \mathrm{PIB}$ noncalibrated IDIFs provided better testretest variability than both calibrated IDIFs and BSIFs. In addition, a better discrimination between patients and healthy controls was found using noncalibrated IDIFs than using calibrated IDIFs or BSIFs (Fig. 4), which corresponds to the good correlation found for all subjects (see straight lines in Fig. 3). However, IDIFs may be less sensitive to changes in experimental conditions, which should be assessed using a longitudinal study to evaluate differences in tracer binding.

The effect of sticking was probably much less for $(R)$ $\left[{ }^{11} \mathrm{C}\right] \mathrm{PK} 11195$ because the peak of the BSIF was much narrower than for $\left[{ }^{11} \mathrm{C}\right] \mathrm{PIB}$. In addition, differences in Logan $\mathrm{V}_{\mathrm{T}}$ values between BSIF and noncalibrated IDIFs were much lower for $(R)-\left[{ }^{11} \mathrm{C}\right] \mathrm{PK} 11195(3 \pm 21 \%)$ than for $\left[{ }^{11} \mathrm{C}\right] \mathrm{PIB}(61 \pm 13 \%)$.

Limitations

To obtain accurate IDIFs it is necessary that the sampling frequency of the peak of the input curve is high enough. For $\left[{ }^{11} \mathrm{C}\right] \mathrm{PK} 11195$, the peak was sampled in one frame of $5 \mathrm{~s}$ and one frame of $10 \mathrm{~s}$. Although this 10-s frame ideally should have been divided into two frames of $5 \mathrm{~s}$, the good correlation between BSIF- and IDIF-based Logan $V_{T}$ suggest that the effects of sampling were small. However, for $\left[{ }^{11} \mathrm{C}\right]$ verapamil, a previous study [18] has shown that there is a significant differences between test scans in the morning and retest scans in the afternoon due to a difference in blood volume fraction. To measure this blood volume fraction accurately, it is necessary that the sampling 
frequency of the peak of the input curve is high enough. Therefore 5-s frames were used for the $\left[{ }^{11} \mathrm{C}\right]$ verapamil data. $\left[{ }^{11} \mathrm{C}\right]$ Verapamil test-retest data showed that comparable test-retest variability was found between IDIF and BSIF and corresponded with the variability found in the study by Lubberink et al. [18]. The results found for $\left[{ }^{11} \mathrm{C}\right]$ verapamil showed that the IDIF is able to correct for the differences in blood volume fraction between morning and afternoon scans. However, in all cases the IDIF should be sampled with sufficiently high frequency, i.e. with short frame durations (5-10 s).

A generally known limitation of any IDIF method is its vulnerability to patient motion. Patient motion at later timepoints can easily lead to under- or overestimation of measured radioactivity. For the current study we visually inspected all data for patient motion between frames. Scans were excluded from the analysis when motion was detected. The good correlation in test-retest between BSIF and (non)calibrated IDIF indicate that the datasets indeed contained no or very small motion. Note that motion of the neck is therefore probably much smaller than that of the head. In the present study, the internal carotid arteries were used, and therefore the IDIF was probably only little affected by motion. However, as mentioned previously by Baudrexel et al. [21] and Mourik et al. [6], for routine applications, an (online) motion correction system must be implemented to safeguard against patient motion

\section{Arterial input as gold standard?}

The results of $\left[{ }^{11} \mathrm{C}\right]$ PIB suggest that both BSIF and manual samples were influenced by sticking of the tracer, and therefore may not have been reliable. In addition, in practice there are problems with cannulation or, especially in the case of $\left[{ }^{11} \mathrm{C}\right] \mathrm{PIB}$, clogged lines in about $5 \%$ to $10 \%$ of cases, which lead to study rejection. Based on these observations, it is quite possible that noncalibrated IDIFs are more reliable than BSIFs at least for these tracers. However, manual samples were still necessary for measuring plasma to whole-blood ratios and metabolite fractions. As discussed previously [6], alternative methods exist, but these methods have to be further substantiated for each of the tracers used.

\section{Conclusion}

For $(R)-\left[{ }^{11} \mathrm{C}\right]$ verapamil, accurate IDIFs were obtained using noncalibrated IDIFs. However, for both $\left[{ }^{11} \mathrm{C}\right] \mathrm{PIB}$ and $(R)$ $\left[{ }^{11} \mathrm{C}\right] \mathrm{PK} 11195$, calibration was necessary to obtain IDIFs comparable to the BSIF. However, the observed need for calibration may be explained by the sticking property of both tracers, indicating that BSIF may be affected by sticking and therefore may be unreliable. Consequently, noncalibrated IDIFs may be a good alternative to BSIF as these IDIFs also provided better test-retest variabilities. The present study showed that for different tracers accurate IDIFs may be obtained from dynamic PET studies, obviating the need for arterial sampling. However, manual samples are still necessary for calculating plasma to wholeblood ratios and metabolites.

Acknowledgements This work was financially supported by the Netherlands Organisation for Scientific Research (NWO, VIDI Grant 016.066.309), the American Health Assistance Foundation (Grant A2005026) and Internationale Stichting Alzheimer Research (Grant \#05512). The authors would like to thank Floris H.P. van Velden for his useful comments and the PET radiochemistry and technology staff of the Division of Nuclear Medicine and PET Research for production of isotopes and acquisition of metabolites and PET data.

\section{References}

1. Lammertsma AA, Hume SP. Simplified reference tissue model for PET receptor studies. Neuroimage 1996;4:153-8.

2. Lammertsma AA, Bench CJ, Hume SP, Osman S, Gunn K, Brooks DJ, et al. Comparison of methods for analysis of clinical [11C]raclopride studies. J Cereb Blood Flow Metab 1996;16:42-52.

3. Hall R. Vascular injuries resulting from arterial puncture of catheterization. Br J Surg 1971;58:513-6.

4. Machleder HI, Sweeney JP, Barker WF. Pulseless arm after brachial-artery catheterisation. Lancet 1972;1:407-9.

5. Chen K, Bandy D, Reiman E, Huang SC, Lawson M, Feng D, et al. Noninvasive quantification of the cerebral metabolic rate for glucose using positron emission tomography, 18F-fluoro-2-deoxyglucose, the Patlak method, and an image-derived input function. J Cereb Blood Flow Metab 1998;18:716-23.

6. Mourik JEM, Lubberink M, Klumpers UMH, Lammertsma AA, Boellaard R. Partial volume corrected image derived input functions for dynamic brain studies: methodology and validation for [11C]flumazenil. Neuroimage 2008;39:1041-50.

7. Mourik JE, van Velden FH, Lubberink M, Kloet RW, Berckel BN, Lammertsma AA, et al. Image derived input functions for dynamic high resolution research tomograph PET brain studies. Neuroimage 2008;43:676-86.

8. Price JC, Klunk WE, Lopresti BJ, Lu X, Hoge JA, Ziolko SK, et al. Kinetic modeling of amyloid binding in humans using PET imaging and Pittsburgh Compound-B. J Cereb Blood Flow Metab 2005;25:1528-47.

9. Vogelgesang S, Cascorbi I, Schroeder E, Pahnke J, Kroemer HK, Siegmund W, et al. Deposition of Alzheimer's beta-amyloid is inversely correlated with P-glycoprotein expression in the brains of elderly non-demented humans. Pharmacogenetics 2002;12:535-41.

10. Toornvliet $R$, van Berckel $B N$, Luurtsema $G$, Lubberink $M$, Geldof AA, Bosch TM, et al. Effect of age on functional Pglycoprotein in the blood-brain barrier measured by use of (R)[(11)C]verapamil and positron emission tomography. Clin Pharmacol Ther 2006;79:540-8.

11. Banati RB, Myers R, Kreutzberg GW. PK ('peripheral benzodiazepine')-binding sites in the CNS indicate early and discrete brain lesions: microautoradiographic detection of [3H]PK11195 binding to activated microglia. J Neurocytol 1997;26:77-82.

12. Boellaard $R$, van Lingen A, van Balen SC, Hoving BG, Lammertsma AA. Characteristics of a new fully programmable blood sampling device for monitoring blood radioactivity during PET. Eur J Nucl Med 2001;28:81-9. 
13. Meyer E. Simultaneous correction for tracer arrival delay and dispersion in CBF measurements by the $\mathrm{H} 215 \mathrm{O}$ autoradiographic method and dynamic PET. J Nucl Med 1989;30:1069-78.

14. Lubberink M, Greuter HNJM, Boellaard R, Luurtsema G, Lammertsma AA. Effect of plasma metabolite correction accuracy on kinetic analysis in positron emission tomography. Neuroimage. 2004;22:T119.

15. Gunn RN, Sargent PA, Bench CJ, Rabiner EA, Osman S, Pike VW, et al. Tracer kinetic modeling of the 5-HT1 A receptor ligand [carbonyl11C]WAY-100635 for PET. Neuroimage 1998;8:426-40.

16. Logan J. Graphical analysis of PET data applied to reversible and irreversible tracers. Nucl Med Biol 2000;27:661-70.

17. Schuitemaker A, van Berckel BN, Kropholler MA, Kloet RW, Jonker C, Scheltens P, et al. Evaluation of methods for generating parametric (R)-[11C]PK11195 binding images. J Cereb Blood Flow Metab 2007;27:1603-15.
18. Lubberink M, Luurtsema $G$, van Berckel BN, Boellaard $R$, Toornvliet R, Windhorst AD, et al. Evaluation of tracer kinetic models for quantification of P-glycoprotein function using (R)[11C]verapamil and PET. J Cereb Blood Flow Metab 2007;27:42433.

19. Boellaard R, Knaapen P, Rijbroek A, Luurtsema GJ, Lammertsma AA. Evaluation of basis function and linear least squares methods for generating parametric blood flow images using 15O-water and positron emission tomography. Mol Imaging Biol 2005;7:273-85.

20. Gunn RN, Lammertsma AA, Hume SP, Cunningham VJ. Parametric imaging of ligand-receptor binding in PET using a simplified reference region model. Neuroimage 1997;6:279-87.

21. Baudrexel S, Graf R, Knoess C, Vollmar S, Wienhard K. Derivation of the input function from dynamic PET images with the HRRT. Nuclear Science Symposium Conference Record 2004;6:3890-92. 